\title{
Editorial
}

\section{Advances in Functionalized Materials Research}

\author{
Daniela Predoi, ${ }^{1}$ Mikael Motelica-Heino, ${ }^{2}$ and Philippe Le Coustumer ${ }^{3}$ \\ ${ }^{1}$ National Institute of Materials Physics, P.O. Box MG 07, Bucharest, 077125 Magurele, Romania \\ ${ }^{2}$ ISTO, UMR 7327 CNRS, Université d'Orléans, $1 A$ rue de la Férollerie, 45071 Orléans Cedex 2, France \\ ${ }^{3}$ EA 4592 Géoressources \& Environnement, ENSEGID, Université Bordeaux, 1 allée F. Daguin, 33607 Pessac Cedex, France \\ Correspondence should be addressed to Daniela Predoi; dpredoi@gmail.com
}

Received 11 December 2014; Accepted 11 December 2014

Copyright (C) 2015 Daniela Predoi et al. This is an open access article distributed under the Creative Commons Attribution License, which permits unrestricted use, distribution, and reproduction in any medium, provided the original work is properly cited.

\begin{abstract}
During the last couple of decades an intensive attention has been given by the scientific communities to the development of a variety of nanomaterials such as inorganic, organic, polymeric, biological, and polymer composites for various applications from biomedical to environmental. Of these, the inorganic ones have been the most investigated as their properties can be changed through functionalization. They can also be made multifunctional with the ability to incorporate broad categories of functions relevant for biomedicine and environment.

This special issue is focused on current and expected advances in the area of functionalized nanomaterials. Due to the interdisciplinary nature of the topic, researchers from the scientific community were invited to contribute with a broad range of original research articles as well as review articles on the following topics: design and synthesis of functionalized nanomaterials, structural and morphological characterization of newly functionalized compounds, advanced functionalized materials for biomedical and environmental applications, and functionalized nanomaterials with magnetic properties.

R. V. Ghita et al. reported the synthesis of a new porous nanocomposite material based on tetraethyl orthosilicate (TEOS) coated hydroxyapatite. In their study, the authors have investigated the ability of these new materials to remove $\mathrm{Pb}^{2+}$ ions from aqueous solutions with different concentration and $\mathrm{pH}$ values. Their study showed that the HApTh nanopowders are promising materials for lead ions removal from aqueous solutions with different $\mathrm{pH}$ values, being able to be used in the future for depollution of wastewaters.
\end{abstract}

In his work, S. Zhao presents a review which highlights that the multiferroic properties of heterostructured multiferroic films assembled with clusters prepared by low energy cluster beam deposition can be controlled or improved by tuning the size of the clusters. In his review, he revealed that thin-film heterostructure is not destroyed due to low temperature and energy during LECBD progress, rendering the LECBD technique ideal to prepare multiferroic nanostructure for applications on NEMS devices.

A. Groza and A. Surmeian evidenced the type of the silicon oxide structures in the PDMS layer deposed on different supports in corona discharges using studies performed by reflection-absorption IR spectroscopy coupled with peak fitting. Their study revealed that at high currents $(40 \mu \mathrm{A})$ the distribution of silicon oxide structures in the PDMS layer deposed on aluminium is influenced by the anodization of the $\mathrm{Al}$ substrate.

S. M. Sarkar et al. presented successfully synthesized air and moisture stable SBA-16-supported bis-cinchona alkaloid chiral ligand and demonstrated that SBA-16 silica is an excellent support material for the heterogeneous chiral ligands.

$\mathrm{S}$. Putdum et al. reported the synthesis of bismuth molybdate $\left(\mathrm{Bi}_{2} \mathrm{MoO}_{6}\right)$ nanoplates using the hydrothermal reaction of bismuth nitrate and sodium molybdate. In their work, the authors have also investigated the effect of the reaction temperature and time of photocatalytic nanoplates on phase, morphology, and photocatalytic properties. Their study revealed that $\mathrm{Bi}_{2} \mathrm{MoO}_{6}$ nanoplates synthesized at $180^{\circ} \mathrm{C}$ for $5 \mathrm{~h}$ exhibit the highest photocatalytic efficiency (over 96\%) within $100 \mathrm{~min}$ of visible light irradiation. 
A. Groza et al. reported for the first time the formation of a porous anodic $\mathrm{Al}$ oxide layer in negative corona discharge in the presence of the PDMS/ $\mathrm{H}_{2} \mathrm{O}_{2}$ lying on the surface of the $\mathrm{Al}$ substrate. They revealed that the process was favored by the enhanced infusion of $\mathrm{H}_{2} \mathrm{O}$ and $\mathrm{OH}$ radicals, respectively, by the negative ions of oxygen and neutral species $\left(\mathrm{O}_{3}\right)$ produced in negative corona discharge in air at atmospheric pressure.

A. Bai et al. presented the preparation of pure and $\mathrm{Ce}$ doped $\mathrm{BiFeO}_{3}$ thin films by solution-gelation process and also the investigation of their phase structures and ferroelectric and leakage properties. They have attributed the enhanced ferroelectric properties to the structural transformation due to the Ce doping. Their work provides an available way of enhancing ferroelectric properties and possible multifunctional applications for $\mathrm{BiFeO}_{3}$ based thin films.

C. Guobin et al. reported that they obtain $\mathrm{Fe}_{3} \mathrm{O}_{4}$-PDMS nanocomposites. Their study has shown that the magnetic properties of the nanocomposites depend on the magnetic properties of nanoparticles and that the variation of magnetocapacitance depends on the elastic module and the viscosity of PDMS. By comparing the calculated value with the experimental value, they have demonstrated that the model can well explain the magnetocapacitance effect in $\mathrm{Fe}_{3} \mathrm{O}_{4}$-PDMS nanocomposites.

In their work, T. S. H. Perera et al. summarized some recent progress on the synthesis, properties, and application of lanthanide doped Anps. They highlight the many synthesis methods reported by now in the literature and identified the in situ precipitation method as the most effective method. The review is focused on the new generation of fluorophores called rare earth doped apatite nanoparticles (REAnps) and their ability to emit near infrared radiations which have low absorptivity by tissue chromophores and are suitable for biological system imaging and also discusses the opportunity for future studies on the effective biological applications of REAnps.

In their work, D. Y. Tam and P. K. Lo make a review of the cutting edge research in the DNA nanotechnology field. The review focuses on the important role of DNA in nanotechnology and summarizes recent progress of drug delivery systems based on multidimensional DNA nanostructures and the understanding of cellular uptake mechanism such as their intracellular pathway and pharmacokinetics.

\section{Acknowledgments}

The editors would like to thank the authors who have submitted a manuscript to this special issue. The lead editor thanks all the editors for their time spent in reviewing and assigning reviews for the submitted manuscripts.

Daniela Predoi

Mikael Motelica-Heino Philippe Le Coustumer 

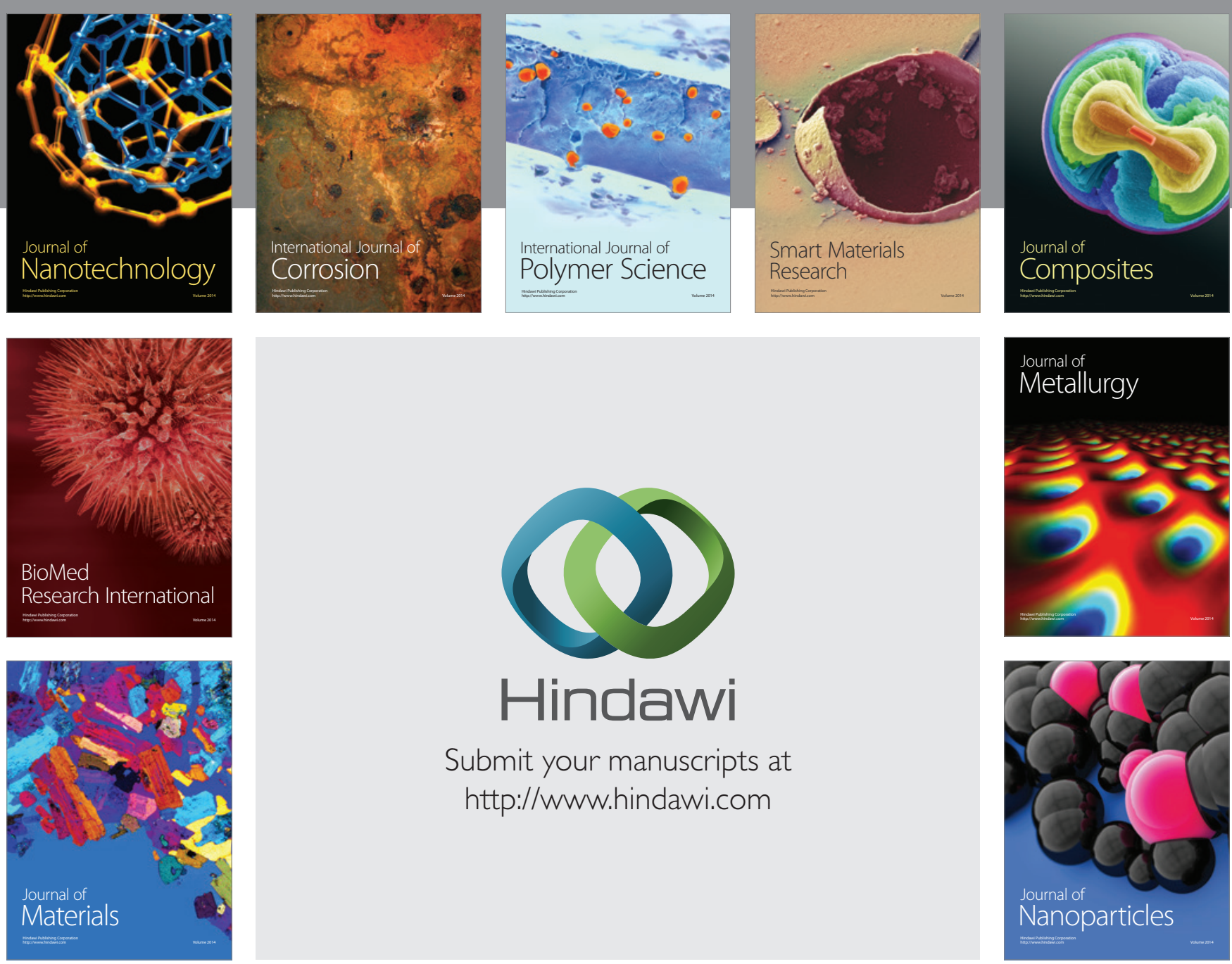

Submit your manuscripts at http://www.hindawi.com
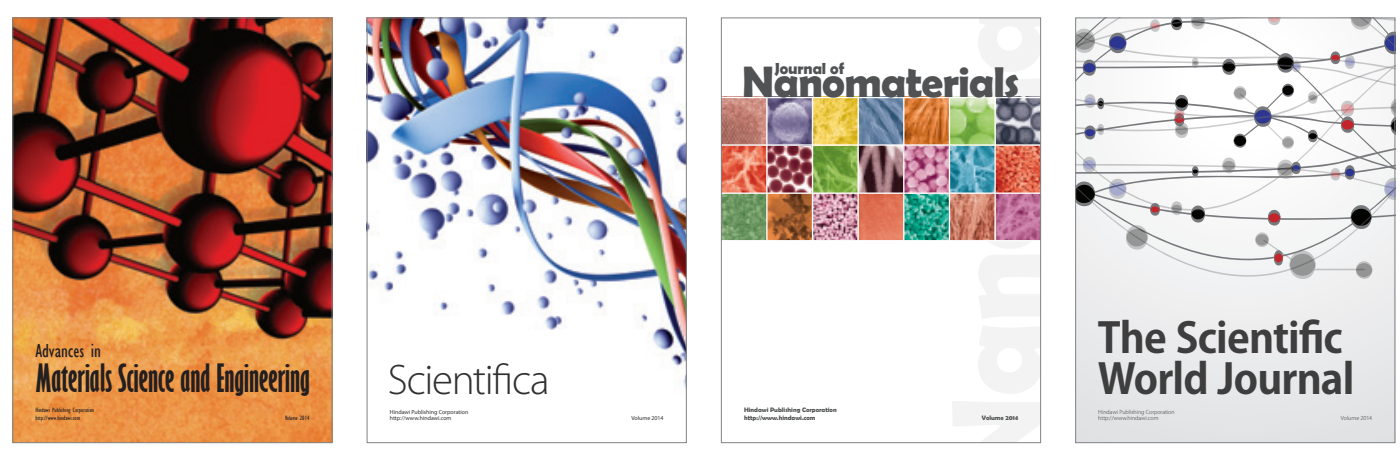

\section{The Scientific World Journal}
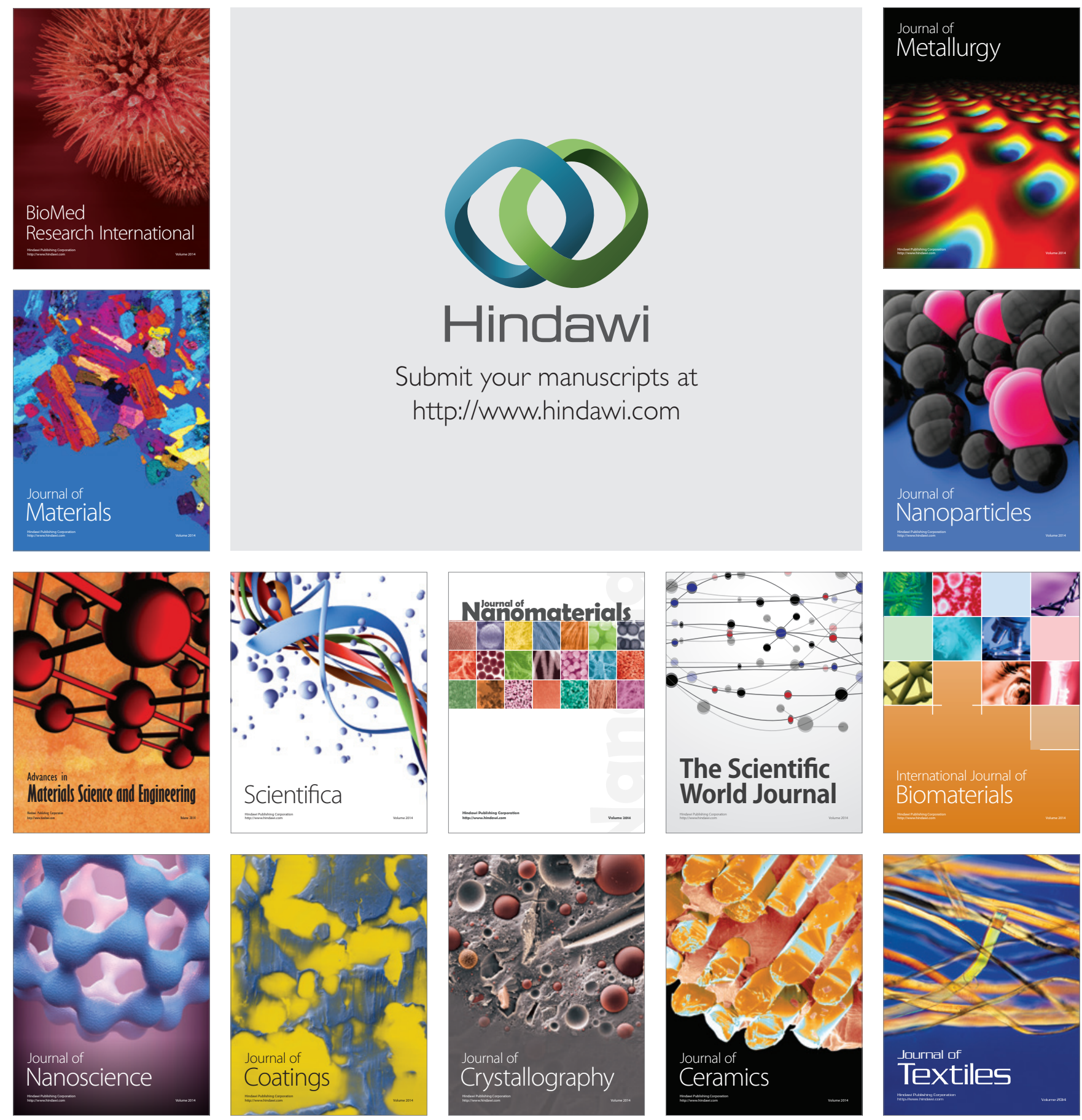